Table 1

Dynamics of symptoms in TOFA treated pts with or without MRI-SI

\begin{tabular}{|c|c|c|c|c|c|c|}
\hline \multirow[t]{2}{*}{ Symptoms } & \multicolumn{3}{|c|}{$\begin{array}{l}\text { MRT-SI (+) } \\
(n=14)\end{array}$} & \multicolumn{3}{|c|}{$\begin{array}{l}\text { MRT-SI (-) } \\
(n=26)\end{array}$} \\
\hline & Baseline & $\begin{array}{l}\text { After } 6 \\
\text { months }\end{array}$ & $p$ & Baseline & $\begin{array}{l}\text { After } 6 \\
\text { months }\end{array}$ & $p$ \\
\hline $\begin{array}{l}\text { Number of digits } \\
\text { with dactylitis }\end{array}$ & $\begin{array}{c}2 \\
{[0 ; 4]}\end{array}$ & $\begin{array}{c}0 \\
{[0 ; 0]}\end{array}$ & 0.008 & $\begin{array}{c}0 \\
{[0 ; 2]}\end{array}$ & $\begin{array}{c}0 \\
{[0 ; 0]}\end{array}$ & 0.003 \\
\hline ESR $(\mathrm{mm} / \mathrm{h})$ & $\begin{array}{c}47 \\
{[26 ; 76]}\end{array}$ & $\begin{array}{c}12 \\
{[6 ; 16]}\end{array}$ & 0.006 & $\begin{array}{c}20 \\
{[6 ; 37]}\end{array}$ & $\begin{array}{c}8 \\
{[6 ; 16]}\end{array}$ & 0.001 \\
\hline WPAI (\%) & $\begin{array}{c}80 \\
{[60 ; 84]}\end{array}$ & $\begin{array}{c}0 \\
{[0 ; 20]}\end{array}$ & 0.007 & $\begin{array}{c}20 \\
{[0 ; 60]}\end{array}$ & $\begin{array}{c}0 \\
{[0 ; 10]}\end{array}$ & 0.128 \\
\hline
\end{tabular}

After 6 months of TOFA therapy, no differences were found between groups of pts with and without MRI-SI in the number of digits with dactylitis $(p=0.47)$, in ESR $(p=0.79)$ and in WPAI $(p=0.93)$

Conclusion: In PsA pts significant association of active MRI-SI was found with dactylitis, high ESR level and WPAI. Use of TOFA in pts with both active MRI-SI and dactylitis demonstrated its high efficacy in reduction of SI inflammation and dactylitis; it also significantly improved pts' work productivity. These findings are important for personalized approach to treatment of PsA.

References:

[1] Brockbank JE et al. Ann Rheum Dis. 2005;64(2):188-90

[2] Mease PJ et al. J Rheumatol 2018;45:1389-96

[3] Gladman DD et al. N Engl J Med 2017;377:1525-36

Disclosure of Interests: ELENA GUBAR: None declared, Tatiana Korotaeva Grant/research support from: Pfizer, Consultant of: Abbvie, BIOCAD, Bristol-Myers Squibb, Celgene, Eli Lilly, Janssen, Merck Sharp \& Dohme, Novartis, Novartis-Sandoz, Pfizer, UCB, Speakers bureau: Abbvie, BIOCAD, Bristol-Myers Squibb, Celgene, Eli Lilly, Janssen, Merck Sharp \& Dohme, Novartis, Novartis-Sandoz, Pfizer, UCB, Yulia Korsakova: None declared, Elena Loginova Speakers bureau: Janssen, Svetlana Glukhova: None declared, Polina Karpova: None declared DOI: 10.1136/annrheumdis-2020-eular.1965

\begin{tabular}{|l|l}
\hline SAT0420 & EFFICACY OF NON-TUMOUR NECROSIS FACTOR \\
BIOLOGICS AND TARGETED SYSTEMIC DISEASE \\
MODIFYING ANTI-RHEUMATIC DRUGS IN THE \\
TREATMENT OF PSORIATIC ARTHRITIS: A \\
SYSTEMATIC REVIEW AND META-ANALYSIS
\end{tabular}

A. Bayley ${ }^{1}$, N. Gullick ${ }^{2} .{ }^{1}$ University of Warwick, Coventry, United Kingdom; ${ }^{2}$ University Hospitals Coventry and Warwickshire, Coventry, United Kingdom

Background: Psoriatic arthritis (PsA) is a systemic, inflammatory condition presenting in approximately $30 \%$ of patients with psoriasis and associated with functional impairment and a reduced health-related quality of life. Current treatment guidelines recommend non-steroidal anti-inflammatory drugs, conventional Disease Modifying Anti-Rheumatic Drugs (cDMARDs) and Tumour Necrosis Factor a inhibitors (TNFi). Recent research has focused on alternative biologic medications which target interleukin (IL) 6, 12/23, 17A, 23 and T Cell co-stimulation, as well as targeted synthetic DMARDs (tsDMARDs) including Janus Kinase inhibitors (JAKi) and Phosphodiesterase 4 inhibitors (PDE4i). Evidence of the safety and efficacy, measured using the American College of Rheumatology-20 (ACR20), has been demonstrated leading to the inclusion of several biologics and tsDMARDs in guidelines. However, it can be argued that ACR50, indicating a $50 \%$ improvement in disease, is a more clinically relevant outcome measure. Objectives: To conduct a systematic review and meta-analysis of the efficacy (ACR50 response) of non-TNFi biologics and tsDMARDs in the treatment of PsA. Methods: A systematic literature search of Embase, MedLine and Web of Science was undertaken to identify randomised controlled trials (RCTs) investigating efficacy and safety of non-TNFi biologics and tsDMARDs published in English from the inception of the databases to September 2019. The Cochrane Risk of Bias tool was used to assess methodological rigour of included trials. A meta-analysis was performed using a random effects model to estimate odds ratios of ACR 50 response vs placebo. A subgroup analysis was performed using patients with previous TNFi exposure.

Results: $21 \mathrm{RCTs}$ were eligible with 6389 participants. Evaluation periods ranged from 12 to 24 weeks. JAKi, PDE4i, IL6i, IL12/23i, IL17Ai and IL23i treatments were more efficacious than placebo for ACR50 response $(p<0.001)$ (Figure 1). Only tofacitinib (JAKi), secukinumab (IL17Ai) and ixekizumab (IL17Ai) were able to demonstrate efficacy at the ACR50 level in participants with prior TNFi exposure $(p<0.0001)$ (Figure 2). All treatments demonstrated an adequate safety profile.

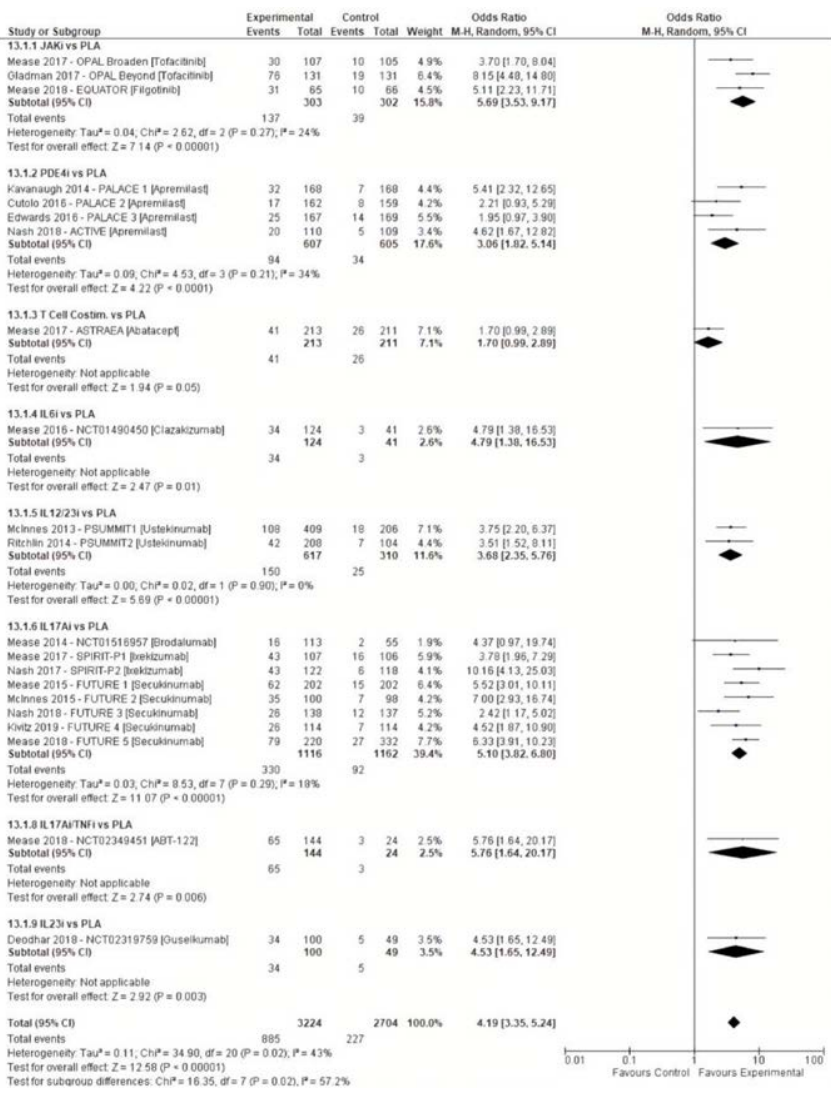

Figure 1. Forest plot of achieving American College of Rheumatology-50 with treatment versus placeboM-H, Mantel-Haenzel; $\mathrm{Cl}$, confidence interval; JAKi, Janus Kinase inhibitor; PLA placebo; df, degrees of freedom; PDE4i, Phosphodiesterase 4 inhibitor; IL6Ai, Interleukin 6 inhibitor; IL12/23i, Interleukin 12/23 inhibitor; IL17Ai, Interleukin 17A inhibitor; TNFi, Tumour necrosis factor inhibitor; IL23i, Interleukin 23 inhibito

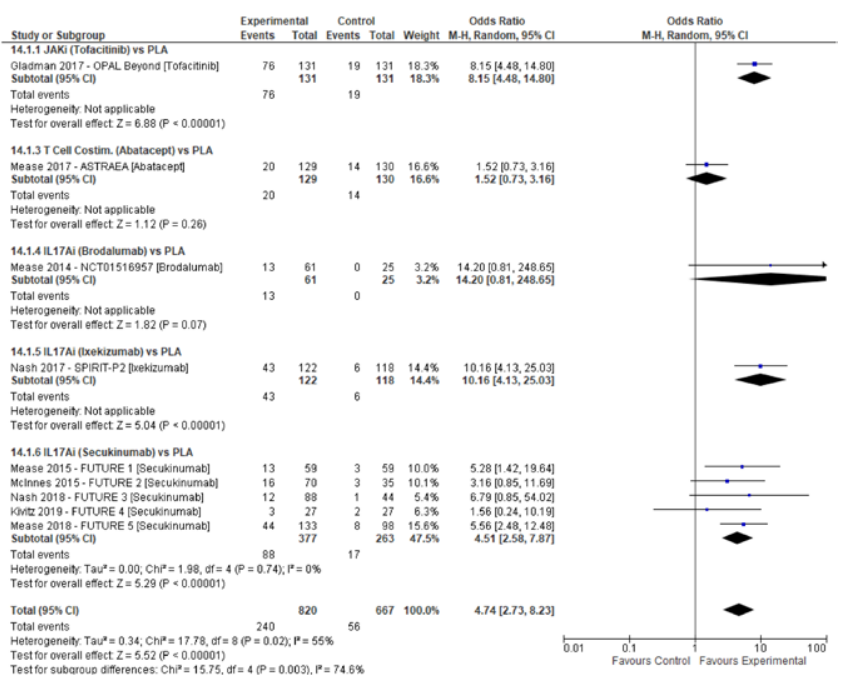

Figure 2. Forest plot of achieving American College of Rheumatology-50 with treatment versus placebo in tumour necrosis factor inhibitor-exposed subgroupM- $\mathrm{H}$, Mantel-Haenzel; $\mathrm{Cl}$, confidence interval; JAKi, Janus Kinase inhibitor; PLA, placebo; df, degrees of freedom; PDE4i, Phosphodiesterase 4 inhibitor; IL6Ai, Interleukin 6 inhibitor; IL12/23i, Interleukin 12/23 inhibitor; IL17Ai, Interleukin 17A inhibitor; IL23i, Interleukin 23 inhibitor

Conclusion: Non TNFi biologics and tsDMARDs are able to demonstrate $50 \%$ improvement with adequate safety profiles. These therapies are often used in patients who are inadequate responders to TNFi but there is less robust data in this specific patient group. Studies with clinically relevant primary endpoints should be considered in this patient population. 
Disclosure of Interests: None declared

DOI: 10.1136/annrheumdis-2020-eular.4742

\section{SAT0421 GUSELKUMAB DEMONSTRATED AN INDEPENDENT TREATMENT EFFECT ON FATIGUE AFTER ADJUSTMENT FOR CLINICAL RESPONSE (ACR20) IN PATIENTS WITH PSORIATIC ARTHRITIS: RESULTS FROM PHASE-3 TRIALS DISCOVER 1 \& 2}

P. Helliwell ${ }^{1}$, P. Rahman ${ }^{2}$, A. Deodhar ${ }^{3}$, A. Kollmeier ${ }^{4}$, E. C. Hsia ${ }^{4,5}$, B. Zhou ${ }^{4}$, X. Lin ${ }^{4}$, C. $\mathrm{Han}^{4}$, P. J. Mease ${ }^{6}{ }^{1}$ Univ of Leeds, Leeds, United Kingdom; ${ }^{2}$ Memorial Univ of Newfoundland, St John's, Canada; ${ }^{3}$ Oregon Health \& Science Univ, Portland, United States of America: ${ }^{4}$ Janssen Research \& Development, LLC, Spring House, United States of America; ${ }^{5} U$ Penn Med Ctr, Philadelphia, United States of America; ${ }^{6}$ Swedish Med Ctr/Providence St. Joseph Health and U Wash School of Med, Seattle, United States of America

Background: DISCOVER 1 and 2 are phase- 3 trials of guselkumab (GUS, a monoclonal antibody that specifically binds the p19-subunit of IL-23) in patients with psoriatic arthritis (PsA). In both trials, treatment with GUS led to significantly more improvement than placebo (PBO) in the primary endpoint (ACR20) as well as in other measures of arthritis and psoriasis at week (W) 24. ${ }^{1,2}$

Objectives: To evaluate the effect of GUS on fatigue in DISC 1 \& 2 using the patient reported outcome (PRO) FACIT-Fatigue, which has demonstrated content validity and strong psychometric properties in clinical trials. ${ }^{3}$

Methods: DISC 1 \& 2 enrolled patients with active PsA, despite nonbiologic DMARDS and/or NSAIDS, who were mostly biologic naïve except for $\sim 30 \%$ of patients in DISC 1 who had received 1-2 TNFi. Patients were randomized (1:1:1) in a blinded fashion to subcutaneous GUS $100 \mathrm{mg}$ at W0 and W4 then every (q) $8 \mathrm{~W}$, to GUS $100 \mathrm{mg} \mathrm{q} 4 \mathrm{~W}$, or to matching PBO. Concomitant treatment with select non-biologic DMARDS, oral corticosteroids, and NSAIDs was allowed. The FACIT-Fatigue is a 13-item PRO instrument assessing fatigue and its impact on daily activities and function over the past seven days, with a total score ranging from 0 to 52 , higher score denoting less fatigue. A change of $\geq 4$ points is identified as clinically meaningful. ${ }^{3}$ Change from baseline in FACIT-Fatigue was analyzed using MMRM (Figure). Independence of treatment effect on FACIT-Fatigue from effect on ACR20 was assessed using Mediation Analysis ${ }^{4}$ (Table) to estimate the natural direct effect (NDE) and natural indirect effect (NIE) mediated by ACR20 response. Results: At baseline in DISC 1 \& 2, the mean FACIT-fatigue scores (SD) were 30.4 (10.4) and 29.7 (9.7), respectively, indicating moderate to severe fatigue. In

Figure. Week-24 Changes from Baseline in FACIT-Fatigue in the DISCOVER 1 and 2 Trials of Guselkumab in Patients with Psoriatic Arthritis

A. DISCOVER 1 Trial

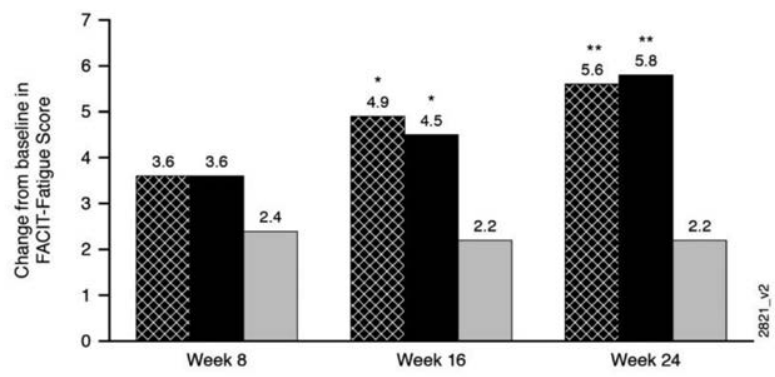

\GUS every 8 Wk (n=126-127) - GUS every 4Wk (n=128) $\square$ PBO (n=125-126)

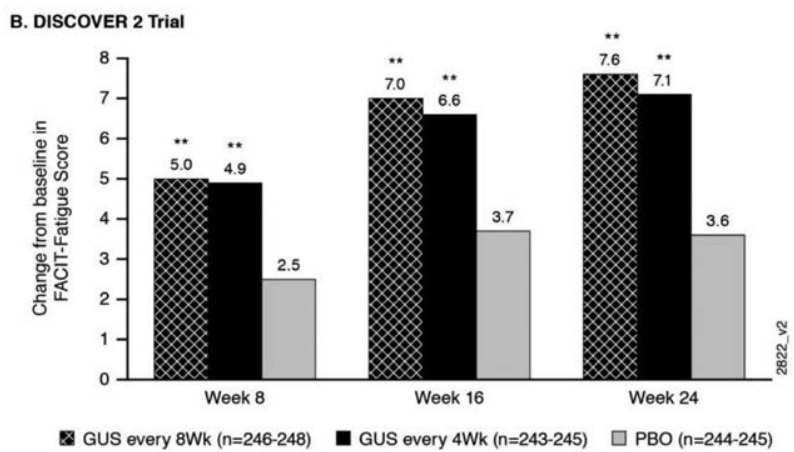

"P vs. PBO $\leq 0.013, \cdots P$ vs. PBO $<0.001$

FACIT=Functional Assessment of Chronic IIIness Therapy, GUS=guselkumab, PBO=placebo, Wk=Week Analysis of changes from baseline in FACIT-Fatigue scores used Mixed-Effect Model Related Measures (MMRM), with factors including treatment group, baseline use of non-biologic DMARDs, CRP status ( $>2.0$ or $\leq 2.0 \mathrm{mg} / \mathrm{dL}$ ), and for DISCOVER 1 only, prior use of TNF inhibitors.
Table. Mediation Analysis of the Effect of ACR 20 Response on Change from Baseline in FACIT-Fatigue Score at Week 24

\begin{tabular}{|c|c|c|c|}
\hline & Effect & $\begin{array}{c}\text { GUS } 100 \text { mg q8W vs. } \\
\text { PBO } \\
\text { Estimate }(95 \% \mathrm{Cl})\end{array}$ & $\begin{array}{c}\text { GUS } 100 \mathrm{mg} \text { q4W } \\
\text { vs. PBO } \\
\text { Estimate }(95 \% \mathrm{Cl})\end{array}$ \\
\hline \multirow[t]{5}{*}{ DISCOVER 1} & NDE & $0.36(-1.7,2.4)$ & $2.60(0.6,4.5)^{\star}$ \\
\hline & NIE & $2.75(1.4,4.3)^{\star}$ & $1.20(0.3,2.3)^{*}$ \\
\hline & Total Effect & $3.12(1.0,5.2)^{\star}$ & $3.79(1.9,5.4)^{\star}$ \\
\hline & Proportion Independent & $11.7 \%$ & $68.5 \%$ \\
\hline & Proportion Mediated & $88.3 \%$ & $31.5 \%$ \\
\hline \multirow[t]{5}{*}{ DISCOVER 2} & NDE & $1.44(-0.1,3.0)$ & $2.49(1.0,4.1)^{\star}$ \\
\hline & NIE & $2.53(1.6,3.6)^{\star}$ & $1.09(0.4,1.9)^{\star}$ \\
\hline & Total Effect & $3.97(2.4,5.5)^{\star}$ & $3.58(2.1,5.0)^{\star}$ \\
\hline & Proportion Independent & $36.3 \%$ & $69.7 \%$ \\
\hline & Proportion Mediated & $63.7 \%$ & $30.3 \%$ \\
\hline
\end{tabular}

${ }^{*} \mathrm{P}$ vs placebo $<0.02$

NDE=Natural Direct Effect (effect on FACIT-F beyond effect on ACR20), NIE=Natural Indirect Effect (effect on FACIT-F mediated by ACR20)

Mediation analysis ${ }^{4}$ used linear and logistics regression models with Bootstrapping method

both DISCOVER 1 \& 2 trials, treatment with GUS led to improvements in FACIT-Fatigue scores compared with PBO as early as W8 (Figure). 54\%$63 \%$ of GUS patients compared with $35 \%-46 \%$ of PBO patients achieved clinically meaningful improvement ( $\geq 4$ points) in FACIT-Fatigue $(P \leq 0.003)$. Mediation analysis revealed that the independent treatment effects on fatigue after adjustment for ACR20 response (Natural Direct Effect [NDE], Table) were $12-36 \%$ in the q8W GUS dosing group and $69 \%-70 \%$ in the q4W GUS group.

Conclusion: In 2 phase-3 trials, treatment with GUS of patients with active PsA led to significant improvements compared to PBO in fatigue, including substantial effects on FACIT-Fatigue that were independent of the effects on ACR 20, especially for the q4W dosing group.

References:

[1] Deodhar et al. ACR 2019. Abstract \#807. Arthr Rheumatol. 2019;71 S10: 1386

[2] Mease et al. ACR 2019. Abstract \# L13. Arthr Rheumatol. 2019;71 S10:5247

[3] Cella et al. Journal of Patient-Reported Outcomes. 2019;3:30

[4] Valeri et al. Psychologic Meth. 2013;18:137

Acknowledgments: None

Disclosure of Interests: Philip Helliwell: None declared, Proton Rahman Grant/research support from: Janssen and Novartis, Consultant of: Abbott, AbbVie, Amgen, BMS, Celgene, Lilly, Janssen, Novartis, and Pfizer., Speakers bureau: Abbott, AbbVie, Amgen, BMS, Celgene, Lilly, Janssen, Novartis, Pfizer, Atul Deodhar Grant/research support from: AbbVie, Eli Lilly, GSK Novartis, Pfizer, UCB, Consultant of: AbbVie, Amgen, Boehringer Ingelheim, Bristol Myer Squibb (BMS), Eli Lilly, GSK, Janssen, Novartis, Pfizer, UCB, Speakers bureau: AbbVie, Amgen, Boehringer Ingelheim, Bristol Myer Squibb (BMS), Eli Lilly, GSK, Janssen, Novartis, Pfizer, UCB, Alexa Kollmeier Shareholder of: Johnson \& Johnson, Employee of: Janssen Research \& Develop ment, LLC, Elizabeth C Hsia Shareholder of: Johnson \& Johnson, Employee of: Janssen Research \& Development, LLC, Bei Zhou Shareholder of: Johnson \& Johnson, Employee of: Janssen Research \& Development, LLC, Xiwu Lin Employee of: Janssen Research \& Development, LLC, Chenglong Han Employee of: Janssen Research \& Development, LLC, Philip J Mease Grant/ research support from: Abbott, Amgen, Biogen Idec, BMS, Celgene Corporation, Eli Lilly, Novartis, Pfizer, Sun Pharmaceutical, UCB - grant/research support, Consultant of: Abbott, Amgen, Biogen Idec, BMS, Celgene Corporation, Eli Lilly, Novartis, Pfizer, Sun Pharmaceutical, UCB - consultant, Speakers bureau: Abbott, Amgen, Biogen Idec, BMS, Eli Lilly, Genentech, Janssen Pfizer, UCB - speakers bureau DOI: 10.1136/annrheumdis-2020-eular.401

\section{SAT0422 2 FIRST-LINE CSDMARD MONOTHERAPY RETENTION IN PSORIATIC ARTHRITIS: METHOTREXATE OUTPERFORMS SULFASALAZINE}

M. Jacobs $^{1,2}$, J. Pouw ${ }^{1,2}$, P. Welsing ${ }^{1}$, T. R. Radstake ${ }^{1,2}$, E. Leijten ${ }^{1,2} .{ }^{1}$ UMC Utrecht, Dept. of Rheumatology and Clinical Immunology, Utrecht, Netherlands; ${ }^{2}$ UMC Utrecht, Center for Translational Immunology, Utrecht, Netherlands

Background: Conventional synthetic disease modifying anti-rheumatic drugs (csDMARDs) are the first-line treatment for psoriatic arthritis (PsA), but there is conflicting data regarding their efficacy and scarce reports describing the duration of use (drug retention) of csDMARD in this population. Their position in treatment recommendations is a matter of growing debate due the availability of alternative treatment options with higher levels of evidence. 